\title{
A FORMULATION APPROACH TO QUANTIFY THE ABUNDANCE OF CORAL GENERA
}

\author{
Suharsono and Giyanto \\ Research Center for Oceanography - Indonesian Institute of Sciences, Jakarta - Indonesia \\ e-mail: suharsono@lipi.go.id
}

\begin{abstract}
A formulation approach to quantify the abundance of coral genera is considered important to obtain basic information necessary in determining the potency and condition of coral, and one application can also be used to set quota for coral trade. The line intercept method has been used in five different area throughout Indonesian archipelago representing prestine area to heavy disturbances. Based on the number of occurrence, the genera dominance, the size of colony and the coral coverage in each study area was assigned scale, weight and value. The calculation gave the range of Total Value (TV) from 5-20 and the assignment abundance category of coral genera is 17-20 very common, 14-16 common, 11-13 uncommon, 8 -10 rare, and 5-7 very rare. The categorization of each coral genus of certain area can be used to consider whether it can be harvested or not. Suggestion based on this study as follow: coral genera categorized as "very common" can be harvest, coral genera categorized as "common" can be harvest with caution, coral genera categorized as "uncommon", harvest are limited, coral genera as "rare", harvest are strictly limited and coral genera as "very rare" are prohibited to harvest.
\end{abstract}

Keywords: Abundance, Harvest, Coral genera

\section{INTRODUCTION}

Indonesia is the world's largest shallow water regions consisting of the Sunda shelf in the west and Sahul shelf in the east. In the middle part are a deep sea basins, throughs and deep sea trenches. The numerous large and small islands divided the marine waters of the region into different seas connected by many channel passages and straits. The hub of unique and complex set of physical, chemical and biological interaction related to its geological history, the Indonesian archipelago is one of the region having the richest marine diversity in the world. This diversity arose in the ancient Tethys seas. Results from several studies show that Indonesia can justify claim to be the location of the world's greatest biological diversity (Tomascik et al., 1997; Moosa, 1999). At least 2,500 species offish, 590 of species stony corals, 42 species of mangrove, 13 species of sea grass, 782 species of algae, 850 species of sponge, 2,500 species of mollusc, 1,500 species of crustacean and 745 species of echinoderm (Moosa, 1999; Veron, 2002). Recent study also shows that Indonesia is the home of the greatest diversity of
Acropora corals (94 species), which represent $84 \%$ of the world's Acropora (113 species). The greatest member of species recorded in any one regions was 78, recorded for the Tomini bay in central Sulawesi (Wallace et al., 2001). The high diversity of coral in Indonesia is due to a great variety of their habitats, such as reefs in open sea, in sheltered coastal water, in inland bays, etc. Refuge habitats were also present along the Asian Sunda shelf and the Australian Sahul shelf. These habitats are equally important in the maintenance of the species richness of marine organisms in general, coral in particular.

Indonesian coral reef ecosystems are very vital for coastal human communities and exhibit great resilience to a wide range and intensities of natural disturbance. Coral reefs are also very sensitive to a wide spectrum of anthropogenic impact (Hopley and Suharsono, 2000). Therefore coral reef resources need to be managed in an integrated manner. It is important to ensure continuous ecological function of shallow-water marine ecosystem, which protects wide range of goods and services that are dependent on their continuous well being. The marine aquarium trade 
involves the capture and removal of living organisms, including coral from their habitat. The impact of the marine aquarium trade can be seen and defined on number of colonies of coral removed from reefs (Green and Shirley, 1999). The fundamental question is whether the reduction has already the ecologically significant impacts, whether the population reductions cause damages to coral reef, and are the coral reef has the ability to recover. It is difficult task to monitor the impact of coral trade since coral reefs may be subjected to other anthropogenic impacts unrelated to the marine aquarium trade. Destructive fishing technique (bombing), cyanide fishing, pollution and sedimentation, can and has caused damaging impact on coral reefs.

The vast expanse of Indonesian territorial seas and the great number of coral species that exist therein, make stock assessment of coral species a difficult task to do. Meanwhile, the distribution pattern and habitat preference of corals differ from one species to another, making it more complicated to assess the potency of coral species. Other problems have to do with physical aspects, e.g. research activities in the sea are hampered by underwater visibility, sea current, wave action and weather.

Other constraint confronting effort in stock assessment of corals relates to biological and ecological characters of the coral itself. Corals are not always evenly distributed, they can be distributed randomly or in patches. Not rarely, coral distributions around an island are very diverse, they can be homogeneous or heterogeneous, depending on the locality. In a relatively protected area the structure of coral ecosystem will be different from that in the open waters. Coral distribution in the windward side of current will be different from that on the leeward side. Vertical distribution differs from horizontal distribution. Some coral species are adapted to living on a wide range of depths, namely from shallow waters to deeper waters, others live only in a limited environment either shallow waters or deep waters.

Corals also exhibit differing habitat preference. Some species prefer to live in shallow waters with high penetration of light, others prefer to grow in an area protected from direct sunlight. The Pocilloporid group prefers an open area with strong wave energy, the Acroporid group prefers an open area with moderate wave energy, while the Poritoid prefers a protected area with weak wave energy.
Some coral species like to grow on a soft substrate, while others prefer hard bottom. A number of coral species adapt themselves to a turbid environment, while others require relatively clear water. Certain species tend to be autotrophic, especially those which live in clear water, while others are more heterotrophic, particularly the ones which live in turbid water. In view of the variation in the distribution pattern and the differing characteristic of coral species, and taking into consideration the habitat preference among coral species, it is therefore imperative that a different methodological approach for stock assessment be exercised.

In the previous studies, the presence of coral species in the certain area is usually state qualitatively using category "abundant", "common", "uncommon" or "rare", but there were no standard definition to distinguish among those categories. This present study is the first attempt to make a standard definition in quantifying the presence of coral species in different locations. It is considered important to obtain basic information necessary in determining the potency and condition of coral. One application of its result can be used to set up quota for corals trade. Determining the quota is very important to prevent aquarium coral trade from destroying the coral ecosystems.

\section{METHODS AND STUDY AREA}

The Line Intercept Transect (LIT) method has been used in this study and surveyed using SCUBA. A measuring tape was placed across the reef and any coral colony underlying the line transect was recorded and the length of living coral and other organisms on the tape was measured to the nearest centimeter. The length of line transect is $10 \mathrm{~m}$, parallel to the coast, starting from the reef flat (about 1 or $2 \mathrm{~m}$ deep) towards the reef slope where coral growth is still commonly found. The number of transect depend on the length of the reef. The distance between one transect to the next was $1 \mathrm{~m}$ (Fig. 1). Sessile benthos underlying the line transect were classified into 29 categories at the life form level (English et al., 1994). Field data were entered into a dBase program for storage, checking and analysis.

A total of 668 of Line Intercept Transect were used for data analysis. They were carried out on several areas in Indonesia, namely: 
1) Bakauheni in Lampung, comprises of Rimau Balak Island, Kandang Balak Island and Dua Island (total number of transects $=152$ ), represent area with relatively low disturbance, reef slope $60^{\circ}-70^{\circ}$ with good current flows.

2) Merak in Banten, comprises of Merak Besar Island and Merak Kecil Island (total number of transects $=201$ ). represent area with heavy disturbances due to near busy harbour, reef slope $30^{\circ}-60^{\circ}$ with mud bottom, relatively closed area.

3) Kepulauan Seribu in Jakarta, comprises of Malinjo Island, Sebaru Island, Kayu Angin Semut Island, Kayu Angin Melintang Island (total number of transects $=120$ ), represent area with moderate disturbance, reef slope $30^{\circ}-60^{\circ}$, influenced by moonson current.

4) Jepara, Central Java, comprises of Bandengan coast and Panjang Island (total number of transects $=75$ ), represent area with high sedimentation and close to river discharge, reef slope $10^{\circ}-30^{\circ}$ muddy to sandy bottom.

5) Teluk Cendrawasih, Papua, comprises of Kabuai Island, Nutabari Island, Nuburi Island and Mangguar cape (total number of transects $=120$ ), represent prestine area and remote area, reef slope $80^{\circ}-90^{\circ}$, good current flows.
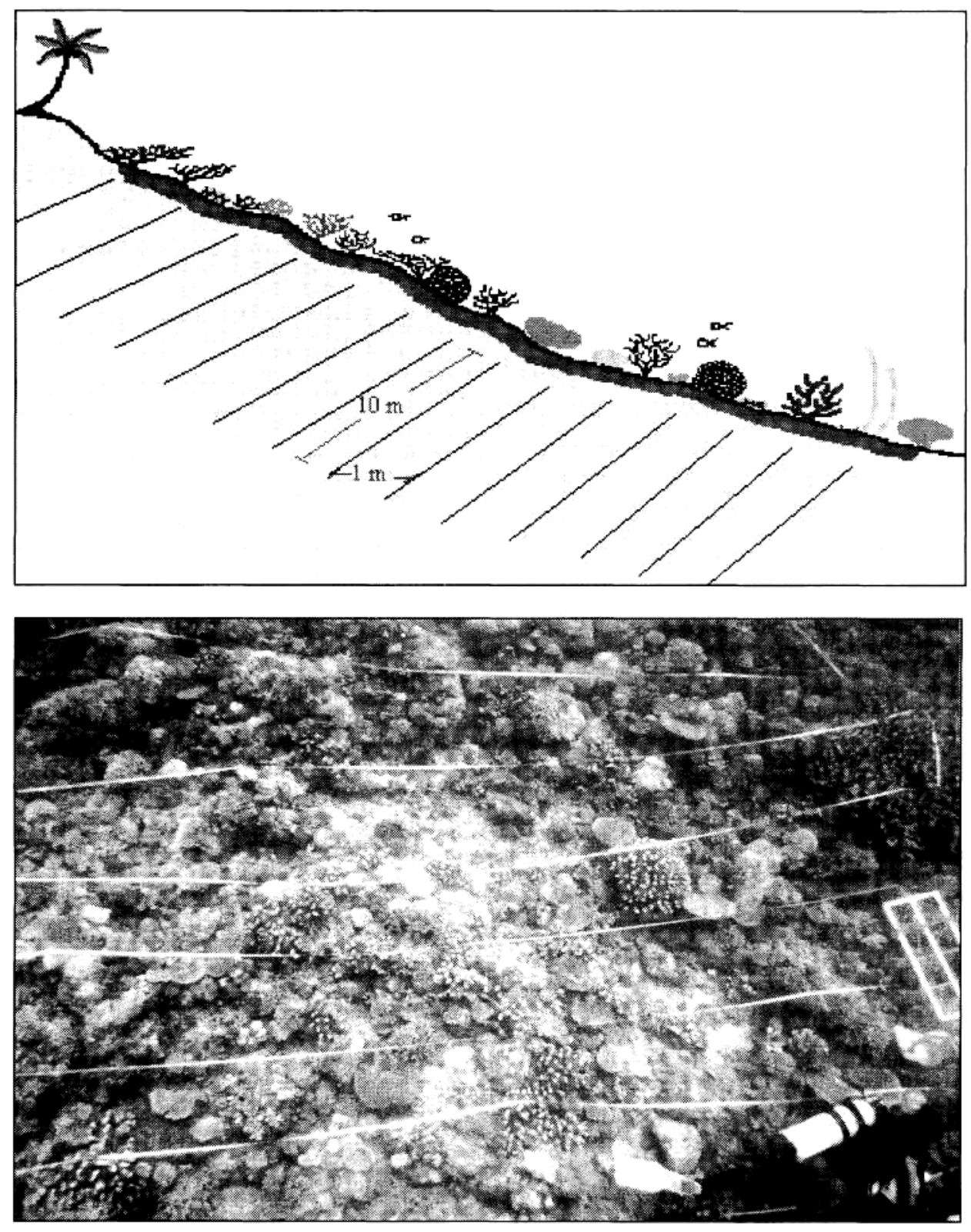

Figure 1. Line Intercept Transect applied in the field. 


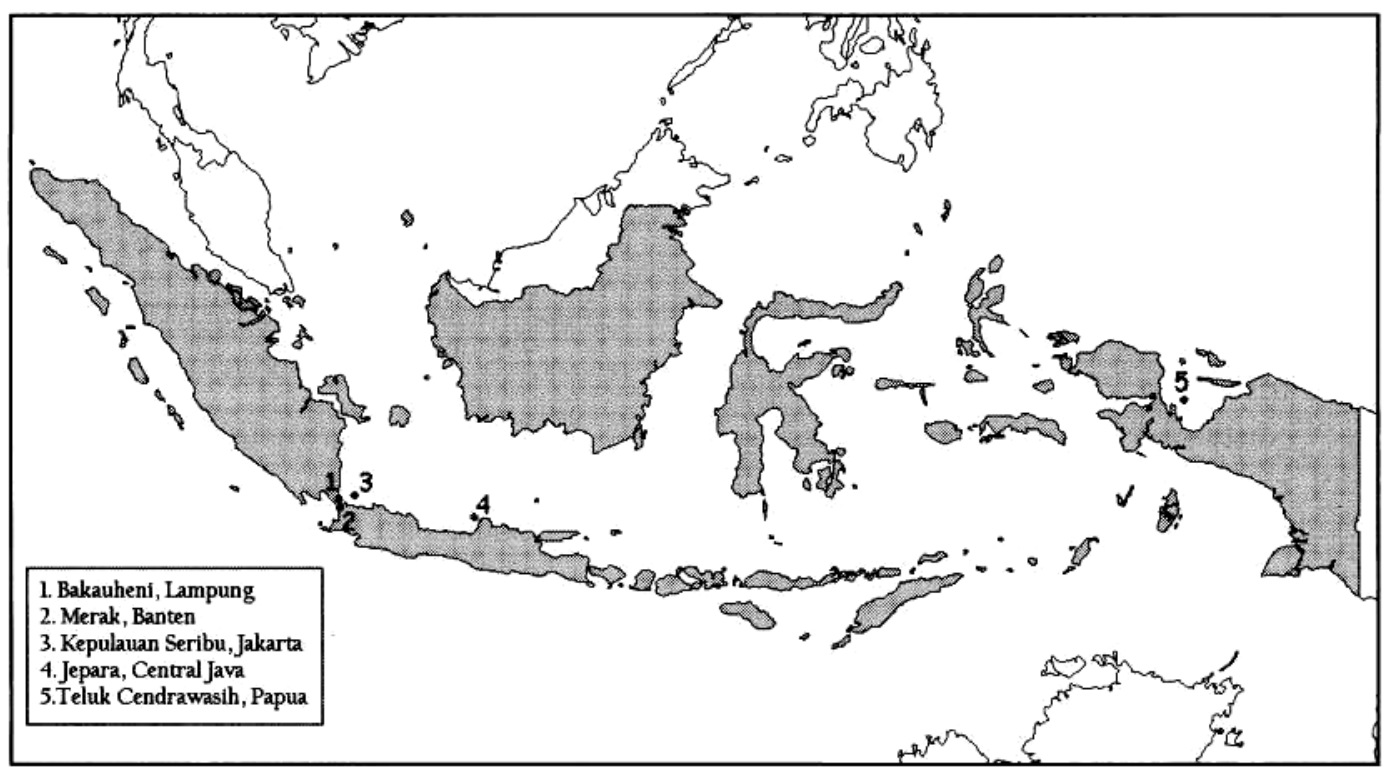

Figure 2. Study area.

\section{Data Analysis}

Based on all collected data, the length of each coral genus can be calculated as well as its frequency (the number of occurrence). Then the size of colony (SoC) of each hard coral genus can be obtained by dividing its length with its frequency. For each hard coral genus, the following units are also calculated:

- Relative Frequency (RF) = the number of occurrence of one genus relatives to the total number of occurrence of hard coral genera.

$$
R F=\frac{T h e \text { number of occurrence of one genus }}{\text { The number of occurrence of hard coral genera }}
$$

- Relative Dominance (RD) $=$ the coverage of one genera relative to the coverage of hard coral genera.

$$
R D=\frac{\text { The coverage of one genus }}{\text { The coverage of hard coral genera }}
$$

Since the value of SoC, RF and RD do not follow the normal distribution pattern, data transformation was made. The ${ }^{10} \log$ transformation was used for those data. Test of KolmogorovSmirnov indicated that the transformed data follow the normal distribution ( $p>0.15$ ) (Fig. 3a, Fig. 3b and Fig. 3c).

There were 4 scales made on the trans-formed data of SoC, RF and RD according to the normal distribution with mean $\mu_{\mathrm{x}}$ and standard deviation $\sigma_{\mathrm{x}}$ :

Scale 1: the value with cumulative probability $\leq 25 \%$

Scale 2: the value with cumulative probability between $25 \%$ and $50 \%$

Scale 3: the value with cumulative probability between $50 \%$ and $75 \%$

Scale 4: the value with cumulative probability $>$ $75 \%$

To put the right scale on the original data easily, the interval values of transformed data were transformed back to the original data (Table 1). Some genera of hard coral have small colony (such as Fungia). For the small colonies, even though the number of occurrences is high, the coverage will not increase dramatically. For this reason, the weight given for SoC and RD are 1, but for RF is 2. The complete value for SoC, RF and RD is as in Table 1.

For the time being, this interval scale for each category is assumed to be representative for condition of coral reef in Indonesia. However, there is the possibility that the interval scale will be changed in the future if there are some new data added.

To decide the action that may be made by decision maker, the categorization of each hard coral genera should be made so as to know whether one genera of hard corals is very rare, rare, many or abundant in one location. Condition 


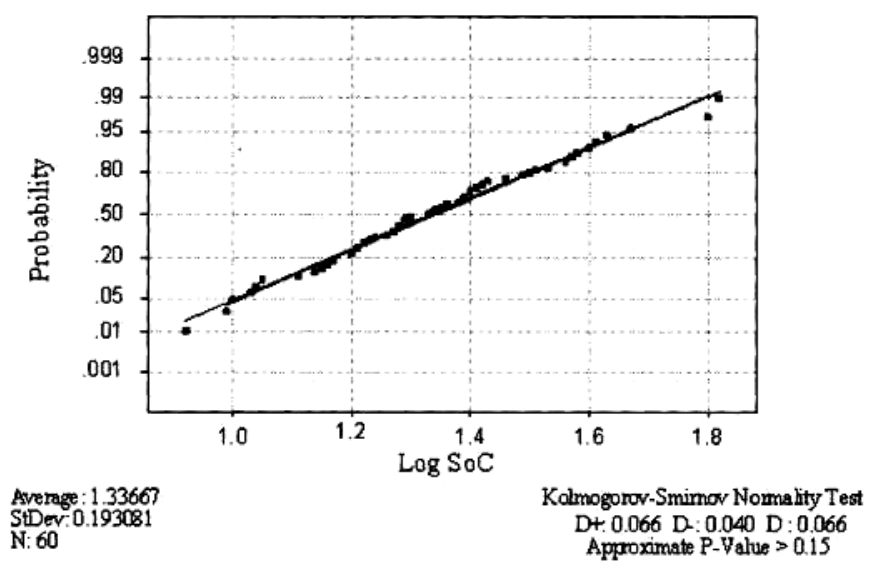

Figure 3a. Normal Probability Plot for $\log$ SoC

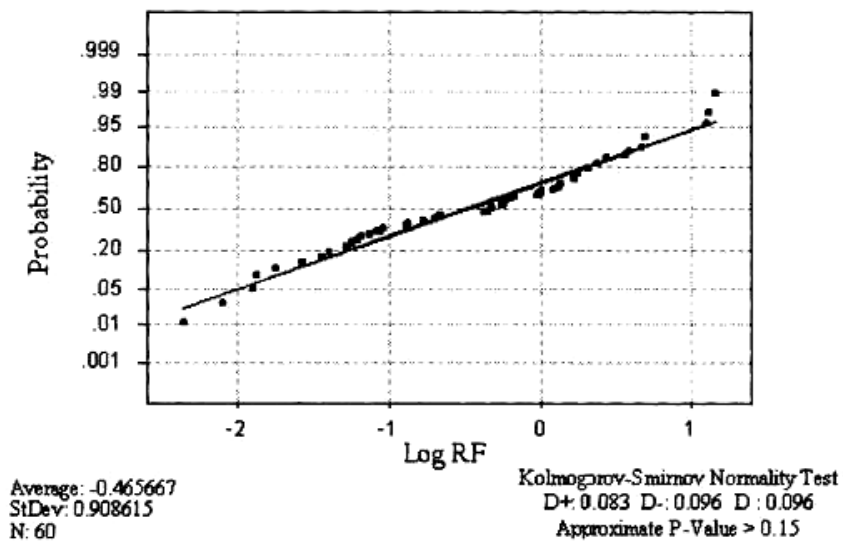

Figure 3b. Normal Probability Plot for Log RF

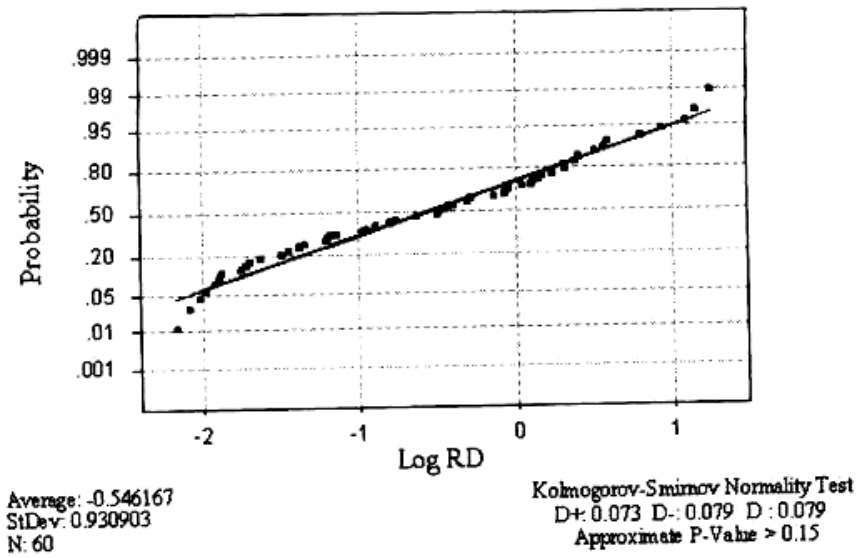

Figure 3c. Normal Probability Plot for Log RD 
Table 1. The interval of original data for each category with their scale, weight and value given.

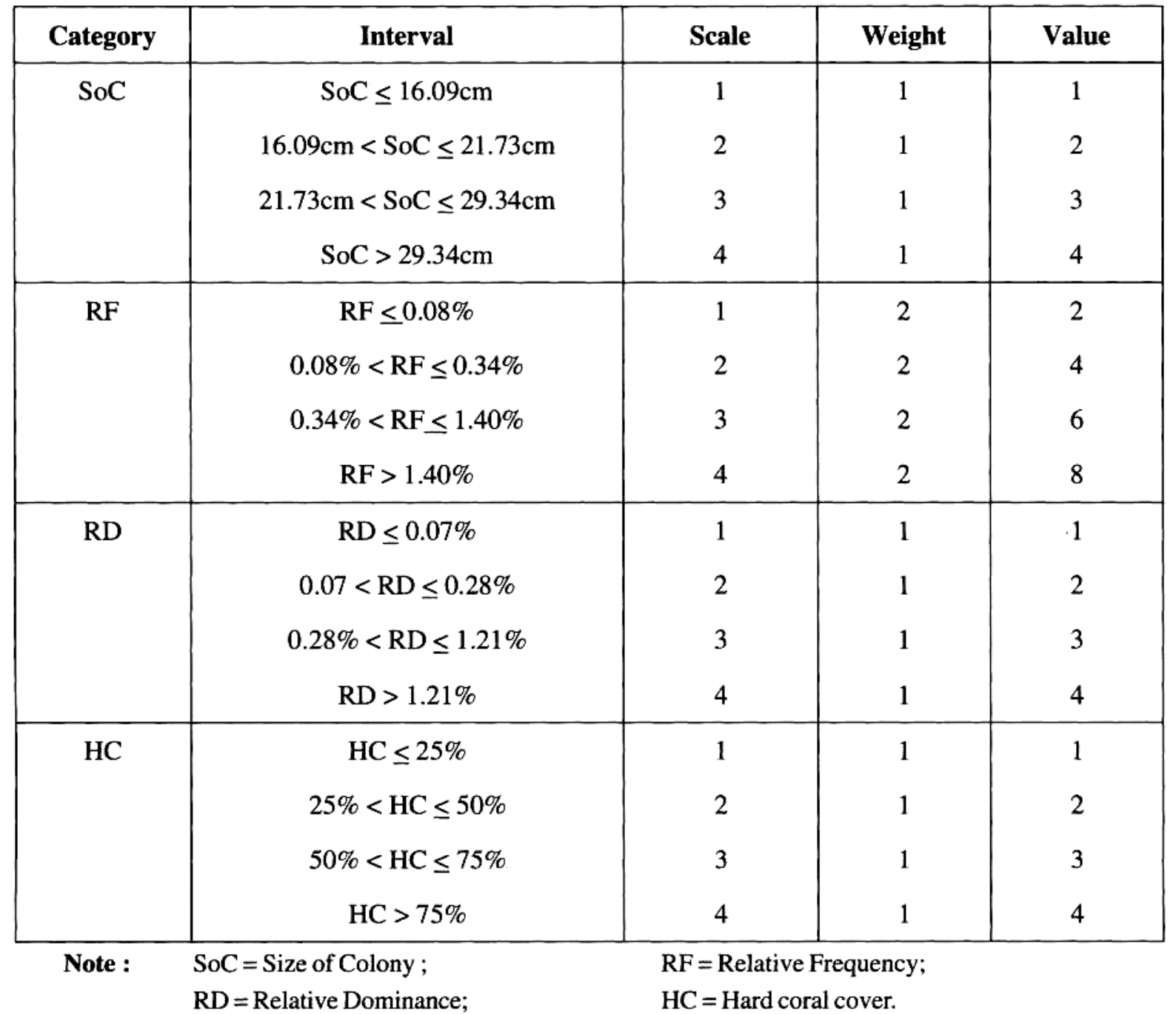

of hard coral cover (HC) should also be considered, besides the fact that SoC, RF and $\mathrm{RD}$ are variable. The low coverage of hard coral genera must have the low scale value. The complete interval scale for $\mathrm{HC}$ is as in Table 1.

Based on the value of SoC, RF, RD and $\mathrm{HC}$ in each location, the total value (TV) can be calculated, as the following :

$$
\mathrm{TV}=\mathrm{SoC}+\mathrm{RF}+\mathrm{RD}+\mathrm{HC}
$$

SoC $=$ Size of Colony ;

RF = Relative Frequency;

$\mathrm{RD}=$ Relative Dominance;

$\mathrm{HC}=$ Hard coral cover

The action that may be made by decision maker depending on the value of TV are in Table 2.
Table 2. Criterion for Decision Making

\begin{tabular}{|c|c|l|}
\hline Interval TV & Criterion & Action taken \\
\hline $17-20$ & Very common & Harvest allowed \\
$14-16$ & Common & Harvest allowed with caution \\
$11-13$ & Uncommon & Harvest limited \\
$8-10$ & Rare & Harvest strictly limited \\
$5-7$ & Very rare & Harvest prohibited \\
\hline
\end{tabular}

Note : TV $=$ Total Value

\section{RESULTS}

Status of abundance coral genera of each location show in Table 3. Acropora, Montipora and Porites belong to coral that can be found in all locations with status common to very common. This is indicated that this coral is very abundance and widely distributed throughout Indonesia. Echinopora, one of corals species has a folious 
growth form, mostly grow and common in the middle reef slope. This coral species was very common found in all locations except in Jepara. This coral species was not found in Jepara might be due to high sedimentation which comes from river mouth nearby the location. Other coral genera such as Oxypora and Pachyseris that have folious growth form were also not found in Jepara. Euphyllia has status from very common to very rare depend on location. This species has wide range distribution from turbid to clear water. Surprisingly this species was found very common in Jepara but rare in Teluk Cendrawasih. Plerogyra was found in all location with status from rare to very rare. Naturally this species was not common and found in hiding place, protected from direct sunlight.

\section{DISCUSSION}

On the basis of their life characteristics, coral reefs may be differentiated into two groups, namely the reef building corals and the non-reef building corals. The latter are solitary species by nature and they live in small patches on soft substrate of a relatively deep waters. Corals trading covers both reef-building and non-reefbuilding corals. Non reef-building corals include among others Trachyphyllia, Nemenzophyllia, Diaseris, and Cycloseris. Coral species are for the most part reef builders. Nonetheless, the demarcation line between reef builders and nonreef builders is not always well defined; as shown by the fact that some species can live both ways, as reef-builders and as non-reef-builders. Blastomussa wellsi and Catalaphyllia jardinei are among the species belonging to this category.

The existence of two coral groups (reef builders and non reef-builders) brings about annoying consequences in connection with the methodology used for assessing the stock of each group. The complexity of coral reefs ecosystem makes monitoring their health an extremely difficult task. Coral reef ecosystem is very variable in both space and time and its makes very difficult in monitoring and assessment technique. Estimates of benthic cover can range from very broad categories to detail survey down to species level. For the reef builders, methods employed include manta tow, video transect, permanent quadrate and line intercept transect should be appropriate whereas for the non-reef builders, it should be the transect belt method.

Knowledge on corals stocks and the marine environment is important for sustainable harvesting of the marine resources. Unfortunately, there is no such attempt to set quota before and there is also no reference can be used as the basis to set the quota. Due to the requirement of several international conventions in order to estimate and determine safe limits for the harvesting of the coral species, the scientists must determine the quantity of corals that can be taken without reducing the natural stock to a level where recruitment of corals stock is seriously threatened.

The scientific basis to set quota should cover various aspects, such as reproduction pattern, growth rate, mortality rate, distribution pattern and abundance of each coral stock. Unfortunately, it would not be possible to carry out such as comprehensive study taking into account that some 590 coral species occur in Indonesia, and that Indonesia has an extended coastal line of 81.000 $\mathrm{km}$. Even though only some 80 coral species have the commercial value for export, yet to study their reproduction pattern, growth rate, mortality rate, distribution pattern and abundance will require quite a long time and need a lot of fund.

The first attempt to analyze and formulate the abundance of corals genera in order to set a recommendation of quota is an important step towards a more long-term sustainable harvesting of the marine resources. It should be pointed out here that it is not possible yet to analyze the material at species level, owing to the fact that some data are still inadequate.

Using relative frequency, relative dominance, size of colony and coral cover calculation, the coral genera can be quantified and the result show that this approach is well represented. For example Acropora, Montipora and Porites which were naturally very common has Total Value above 14 while Plerogyra, Physogyra and Scolymia which was naturally rare has also Total Value under 10 or categorize as rare to very rare (Table 3 ). Beside that, the categorization of each coral genus can be used to consider whether one genus in certain location can be harvested or not. For example Euphyllia can be harvest from Jepara due to the status of this genus is very common in this area but not in Teluk Cendrawasih (Table 3). Euphyllia was found rare and has Total Value of 10 in Teluk Cendrawasih (Table 3). 
Table 3. Status of abundance coral genera of each study area.

\begin{tabular}{|c|c|c|c|c|c|c|c|c|c|c|c|}
\hline \multirow{2}{*}{ No. } & \multirow{2}{*}{ Genus } & \multicolumn{2}{|r|}{ Bakauheni } & \multicolumn{2}{|r|}{ Merak } & \multicolumn{2}{|c|}{ Kepulauan Seribu } & \multicolumn{2}{|r|}{ Jepara } & \multicolumn{2}{|c|}{ Teluk Cendrawasih } \\
\hline & & TV & (Criterion) & TV & (Criterion) & TV & (Criterion) & TV & (Criterion) & TV & (Criterion) \\
\hline 1 & Acanthastrea & - & - & - & - & 10 & (Rare) & 14 & (Common) & 11 & (Uncommon) \\
\hline 2 & Acrhelia & - & - & - & - & - & - & - & - & 10 & (Rare) \\
\hline 3 & Acropora & 18 & (Very common) & 17 & (Very common) & 16 & (Common) & 15 & (Common) & 18 & (Very common) \\
\hline 4 & Alveopora & - & - & - & - & - & - & 6 & (Very rare) & 11 & (Uncommon) \\
\hline 5 & Astreopora & 7 & (Very rare) & - & - & 12 & (Uncommon) & 12 & (Uncommon) & 13 & (Uncommon) \\
\hline 6 & Caulastrea & - & - & - & - & - & - & 16 & (Common) & - & - \\
\hline 7 & Coeloseris & 15 & (Common) & 12 & (Uncommon) & - & - & 15 & (Common) & 14 & (Common) \\
\hline 8 & Coscinaraea & - & - & - & - & 7 & ((Very rare $))$ & - & - & 11 & (Uncommon) \\
\hline 9 & Ctenactis & 12 & (Uncommon) & - & - & 10 & (Rare) & - & - & - & - \\
\hline 10 & Cyphastrea & 13 & (Uncommon) & 12 & (Uncommon) & 11 & (Uncommon) & 16 & (Common) & 14 & (Common) \\
\hline 11 & Dendrophyllia & 9 & (Rare) & - & - & - & - & - & - & - & - \\
\hline 12 & Diploastrea & - & - & - & - & 14 & (Common) & 13 & (Uncommon) & 11 & (Uncommon) \\
\hline 13 & Echinophyllia & - & - & - & - & 12 & (Uncommon) & 10 & (Rare) & 10 & (Rare) \\
\hline 14 & Echinopora & 18 & (Very common) & 17 & (Very common) & 17 & (Very common) & - & - & 18 & (Very common) \\
\hline 15 & Euphyllia & 18 & (Very common) & 5 & (Very rare) & 13 & (Uncommon) & 18 & (Very common) & 10 & (Rare) \\
\hline 16 & Favia & 13 & (Uncommon) & 11 & (Uncommon) & 15 & (Common) & 15 & (Common) & 14 & (Common) \\
\hline 17 & Favites & 16 & (Common) & 16 & (Common) & 15 & (Common) & 16 & (Common) & 13 & (Uncommon) \\
\hline 18 & Fungia & 11 & (Uncommon) & 10 & (Rare) & 14 & (Common) & - & - & 16 & (Common) \\
\hline 19 & Galaxea & 18 & (Very common) & 17 & (Very common) & 14 & (Common) & 17 & (Very common) & 14 & (Common) \\
\hline 20 & Gardineroseris & & - & - & - & - & - & - & - & 7 & (Very rare) \\
\hline 21 & Goniastrea & 17 & (Very common) & 15 & (Common) & 12 & (Uncommon) & 15 & (Common) & 13 & (Uncommon) \\
\hline
\end{tabular}


Table 3. (Continued)

\begin{tabular}{|c|c|c|c|c|c|c|c|c|c|c|c|}
\hline \multirow{2}{*}{ No. } & \multirow{2}{*}{ Genus } & \multicolumn{2}{|r|}{ Bakauheni } & \multicolumn{2}{|r|}{ Merak } & \multicolumn{2}{|c|}{ Kepulauan Seribu } & \multicolumn{2}{|r|}{ Jepara } & \multicolumn{2}{|c|}{ Teluk Cendrawasih } \\
\hline & & TV & (Criterion) & TV & (Criterion) & TV & (Criterion) & TV & (Criterion) & TV & (Criterion) \\
\hline 22 & Goniopora & 15 & (Common) & 8 & (Rare) & 12 & (Uncommon) & 18 & (Very common) & 12 & (Uncommon) \\
\hline 23 & Halomitra & 9 & (Rare) & - & - & 9 & (Rare) & - & - & 7 & (Very rare) \\
\hline 24 & Heliofungia & 12 & (Uncommon) & - & - & 8 & (Rare) & 9 & (Rare) & 8 & (Rare) \\
\hline 25 & Heliopora & 12 & (Uncommon) & 12 & (Uncommon) & 16 & (Common) & - & - & 19 & (Very common) \\
\hline 26 & Hydnophora & 18 & (Very common) & 15 & (Common) & 12 & (Uncommon) & 17 & (Very common) & 19 & (Very common) \\
\hline 27 & Leptastrea & 12 & (Uncommon) & - & - & 12 & (Uncommon) & 13 & (Uncommon) & 10 & (Rare) \\
\hline 28 & Leptoria & & - & - & - & - & - & 13 & (Uncommon) & 13 & (Uncommon) \\
\hline 29 & Leptoseris & 9 & (Rare) & 7 & (Very rare) & 10 & (Rare) & - & - & 13 & (Uncommon) \\
\hline 30 & Lithophyllon & & - & - & - & 10 & (Rare) & 12 & (Uncommon) & - & - \\
\hline 31 & Lobophyllia & 17 & (Very common) & 14 & (Common) & 15 & (Common) & 15 & (Common) & 12 & (Uncommon) \\
\hline 32 & Merulina & 13 & (Uncommon) & 5 & (Very rare) & 16 & (Common) & 13 & (Uncommon) & 15 & (Common) \\
\hline 33 & Millepora & 15 & (Common) & 17 & (Very common) & 17 & (Very common) & - & - & 18 & (Very common) \\
\hline 34 & Montastrea & 18 & (Very common) & 8 & (Rare) & 12 & (Uncommon) & 15 & (Common) & 10 & (Rare) \\
\hline 35 & Montipora & 18 & (Very common) & 15 & (Common) & 15 & (Common) & 16 & (Common) & 17 & (Very common) \\
\hline 36 & Mycedium & 8 & (Rare) & - & - & 13 & (Uncommon) & 12 & (Uncommon) & 15 & (Common) \\
\hline 37 & Oulastrea & - & - & - & - & - & - & 8 & (Rare) & - & - \\
\hline 38 & Oulophyllia & 10 & (Rare) & - & - & 9 & (Rare) & - & - & 8 & (Rare) \\
\hline 39 & Oxypora & 10 & (Rare) & 7 & (Very rare) & 16 & (Common) & - & - & 14 & (Common) \\
\hline 40 & Pachyseris & 16 & (Common) & 8 & (Rare) & 17 & (Very common) & - & - & 19 & (Very common) \\
\hline 41 & Pavona & 14 & (Common) & 16 & (Common) & 17 & (Very common) & 14 & (Common) & 16 & (Common) \\
\hline 42 & Pectinia & 15 & (Common) & 9 & (Rare) & 15 & (Common) & 16 & (Common) & 13 & (Uncommon) \\
\hline
\end{tabular}


Table 3. (Continued)

\begin{tabular}{|l|c|c|c|c|c|c|c|c|c|c|}
\hline \multirow{2}{*}{ Genus } & \multicolumn{2}{|c|}{ Bakauheni } & \multicolumn{2}{|c|}{ Merak } & \multicolumn{2}{c|}{ Kepulauan Seribu } & \multicolumn{2}{|c|}{ Jepara } & \multicolumn{2}{c|}{ Teluk Cendrawasih } \\
\cline { 2 - 10 } & TV & (Criterion) & TV & (Criterion) & TV & (Criterion) & TV & (Criterion) & TV & (Criterion) \\
\hline Physogyra & - & - & - & - & - & - & - & - & 8 & (Rare) \\
Platygyra & 12 & (Uncommon) & 14 & (Common) & 13 & (Uncommon) & 15 & (Common) & 15 & (Common) \\
Plerogyra & 10 & (Rare) & - & - & 9 & (Rare) & 7 & (Very rare) & 8 & (Rare) \\
Pocillopora & 14 & (Common) & 14 & (Common) & 10 & (Rare) & 9 & (Rare) & 16 & (Common) \\
Podabacia & 6 & (Very rare) & - & - & 12 & (Uncommon) & 14 & (Common) & 7 & (Very rare) \\
Polyphyllia & - & - & - & - & - & - & 8 & (Rare) & - & - \\
Porites & 18 & (Very common) & 16 & (Common) & 15 & (Common) & 16 & (Common) & 18 & (Very common) \\
Psammocora & - & - & 12 & (Uncommon & - & - & 10 & (Rare) & 12 & (Uncommon) \\
Pseudosiderastrea & 6 & (Very rare) & 11 & (Uncommon & - & - & & - & - & - \\
Scapophyllia & - & - & - & - & - & - & & - & 10 & (Rare) \\
Scolymia & - & - & - & - & 8 & (Rare) & - & - & - & - \\
Seriatopora & 18 & (Very common) & 14 & (Common) & 14 & (Common) & - & - & 17 & (Very common) \\
Stylocoeniella & - & - & - & - & 11 & (Uncommon) & - & - & 7 & (Very rare) \\
Stylophora & 9 & (Rare) & - & - & 8 & (Rare) & 11 & (Uncommon) & 14 & (Common) \\
Symphyllia & 8 & (Rare) & - & - & 12 & (Uncommon) & 16 & (Common) & 12 & (Uncommon) \\
Trachyphyllia & - & - & - & - & 10 & (Rare) & - & - & - & - \\
Tubastrea & 8 & (Rare) & - & - & - & - & - & - & 7 & (Very rare) \\
Turbinaria & 9 & (Rare) & - & - & - & - & - & - & - & - \\
\hline
\end{tabular}


It is worthwhile to note that this formulation has its own limitation which has something to do with the characters of the corals themselves which have specific preferences. Therefore, the scale given in this writing is valid for Indonesia in general since it is taken from various places in this country. Here the scale of generic abundance at a specific locality (such as Lampung, Merak, Kepulauan Seribu, Jepara, Teluk Cendrawasih) is also presented to show that the scale obtained may differs from the general one which is currently in operation. This sort of situation may happen in view of the fact that a specific genus may be very abundant in one locality, but its distribution pattern is relatively limited. For the above reasons, studies on abundance of coral species on locality intended for coral trade is absolutely necessary in order to obtain the abundance scale of each species.

The methodology used in this activity was LIT for reef-building corals. In applying this methodology it must conform to the standard of sampling design and condition given, so that the result may achieve the needed accuracy. The population study will also be useful to monitor whether or not coral exploitation in a specific locality brings about negative impacts.

In the near future, the same formula will be tested to quantify the abundance of non-reef builder coral species using the transect belt method and maximal sustainable harvest will be calculated with consideration to include the growth rate and mode of reproduction.

\section{REFERENCES}

English, S., Wilkinson, C. and Baker, V. 1994. Survey Manual for Tropical Marine Resources. ASEAN-Australian Marine Science Project: Living Coastal Resources AIMS. Townsville: 368 pp.

Green, E. and Shirley. F. 1999. The Global Trade in Coral. WCMC-World Conservation Press. Biodiversity Ser. 9: $70 \mathrm{pp}$.

Hopley, D. and Suharsono. 2000. The status of coral reefs in Eastern Indonesia. Global Coral Reef Monitoring Network. AIMS: 79 pp.

Moosa, M.K. 1999. The Extent of Knowledge About Marine Biodiversity in Indonesia. In: Rais, J., I.M. Dutton, L. Pantimena, J. Plouffe and R. Dahuri R (eds.) Integrated Coastal and Marine Resource Management Proc. Inter. Symp. Malang, 1998:126-153.

Tomascik, T, A.J. Mah, A. Nontji and M.K. Moosa. 1997. The Ecology of the Indonesian Seas. Vol 7. part 1. Periplus: 642pp.

Veron, J.E.N. 2002. Reef corals of the Raja Ampat Islands, Papua Province, Indonesia. Overview of Scleractinia: 2628.

Wallace, C.C., Z. Richard, and Suharsono. 2001. Regional distribution patterns of Acropora and their use in the conservation of coral reefs in Indonesia. Indonesian Journal of coastal and marine resources Vol.4 No. 1:40-58. 